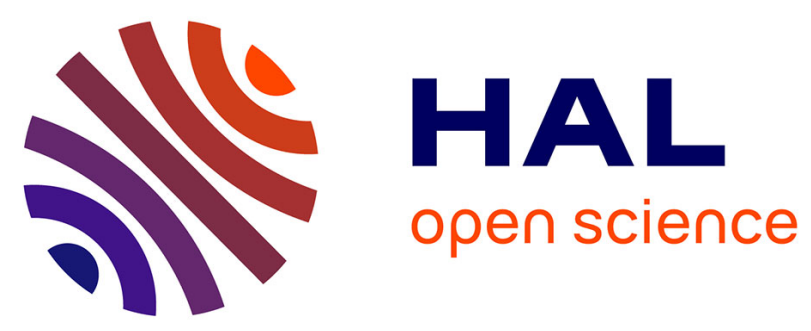

\title{
Signal enhancement of electrochemical biosensors via direct electrochemical oxidation of silver nanoparticle labels coated with zwitterionic polymers
}

\author{
R Geagea, Pierre-Henri Aubert, Philippe Banet, Nicolas Sanson
}

\section{- To cite this version:}

R Geagea, Pierre-Henri Aubert, Philippe Banet, Nicolas Sanson. Signal enhancement of electrochemical biosensors via direct electrochemical oxidation of silver nanoparticle labels coated with zwitterionic polymers. Chemical Communications, 2015, 51 (2), pp.402-405. 10.1039/C4CC07474B . hal-01102096

\section{HAL Id: hal-01102096 \\ https://hal.sorbonne-universite.fr/hal-01102096}

Submitted on 12 Jan 2015

HAL is a multi-disciplinary open access archive for the deposit and dissemination of scientific research documents, whether they are published or not. The documents may come from teaching and research institutions in France or abroad, or from public or private research centers.
L'archive ouverte pluridisciplinaire HAL, est destinée au dépôt et à la diffusion de documents scientifiques de niveau recherche, publiés ou non, émanant des établissements d'enseignement et de recherche français ou étrangers, des laboratoires publics ou privés. 
DOI:

10.1039/C4CC07474B

\title{
Signal enhancement of electrochemical biosensors via direct electrochemical oxidation of silver nanoparticle labels coated with zwitterionic polymer.
}

\author{
R. Geagea, ${ }^{a, b}$ P.-H. Aubert, ${ }^{a}$ P. Banet ${ }^{a^{*}}$ and N. Sanson ${ }^{b, c^{*}}$
}

\begin{abstract}
A new electrochemical label has been developed. It is made of silver nanoparticles (AgNP) coated with a mixture of zwitterionic and biotinylated zwitterionic polymers. These polymers both improve colloidal stability in physiological medium and ensure biorecognition while direct electrochemical oxidation of silver nanoparticles strongly enhances the detection signal. The resulting hybrid nanomaterials are used as label in the electrochemical sensing of avidin using sandwich assays elaborated with the biotinavidin biorecognition system.
\end{abstract}

In recent years, major progress has been achieved in the development of biosensors. ${ }^{1-4}$ New researches in this field face in new challenges such as: (i) the ability to enhance the sensitivity for the detection of traces of disease markers and infectious agents; (ii) the possibility to directly work in biological media.

Nanomaterials are at the core of solutions commonly employed to improve sensitivity. ${ }^{5,6}$ They have been used as well as in optical ${ }^{7}$ and electrochemical ${ }^{8-10}$ biosensors either due to their large specific surface area (to increase the transducer area or to immobilize more labels) or due to their physical properties. For instance, in optical biosensors, slight and long life fluorescence of quantum dots, surface plasmon resonance (SPR), surface enhanced Raman spectroscopy (SERS) and metal enhance fluorescence (MEF) of metallic nanoparticles have particularly been exploited. For electrochemical devices, metallic nanoparticles, carbon nanotubes and graphene have been used to catalyze electrochemical reactions and to improve electron transfer. Nanoparticles have also been used as labels able to generate intense signal in comparison with electroactive molecules or organometallic complexes like ferrocene. Indeed, due to their high number of atoms, huge number of electron can be exchanged through oxidation or reduction. In the first works reporting this last use, the analysis procedure was tedious as a chemical dissolution step was realized before performing titration by anodic stripping. ${ }^{11-15}$ These supplementary steps are time consuming, can be the origin of mistakes and constitute a limit to the development of such labels in electrochemical biosensors that otherwise present many advantages like speed, selectivity, low cost and ease of production and use.
Hence, recent research in this field focuses on direct oxidation of labels especially silver nanoparticle tags. ${ }^{16-18}$ Oxidation of silver deposit is also often encountered in biosensor devices to reveal a biorecognition event and increase the electrochemical signal. ${ }^{19-23}$ As mentioned previously, the colloidal stability of labels in biological environment is an additional crucial requirement for many applications especially in the field of clinical diagnostics. Zwitterionic polymers due to their remarkable anti-fouling properties (resistance to cell, bacteria and protein adsorption) are becoming choice materials in biomedical fields where high stability is required. $^{\text {24-27 }}$ In the present work, we report on a novel label for electrochemical biosensors based on hybrid nanoparticles with a silver core and a zwitterionic polymer shell that will be able to satisfy all requirements (Fig. 1). Indeed, the electrochemical oxidation of silver will contribute to signal enhancement while the zwitterionic polymer chains grafted onto the silver surface will provide excellent stability. Besides these advantages, this elaborated label is very versatile due to the presence of a carboxylic acid as its terminal function, allowing further biofunctionalization with a lot of bioreceptors. This therefore opens up electrochemical biosensor devices to be directed towards various targets. The sensor structure developed to test these hybrid labels is shown in Scheme 1. The biotinylated labels were used in sandwich assays for the detection of avidin as a model protein.

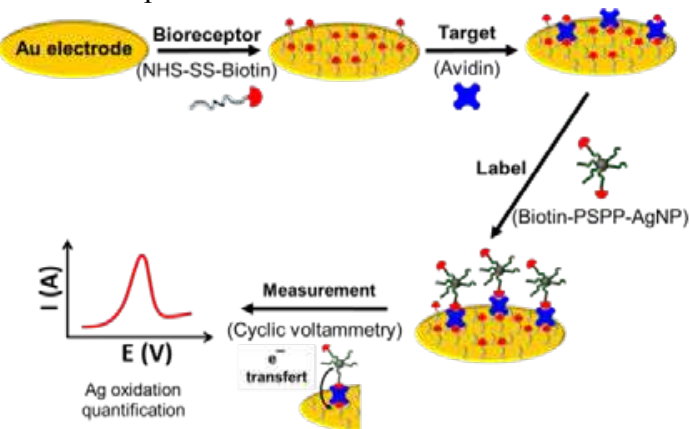

Scheme 1. Principle of the electrochemical biosensor. 
a)

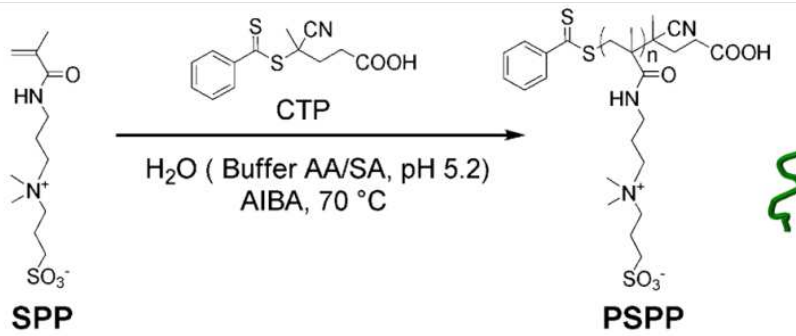

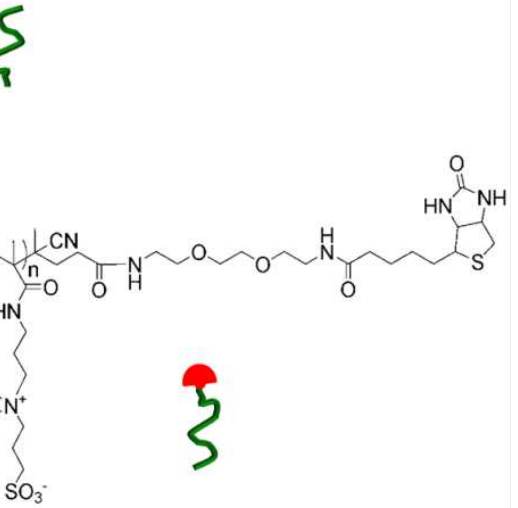

b)

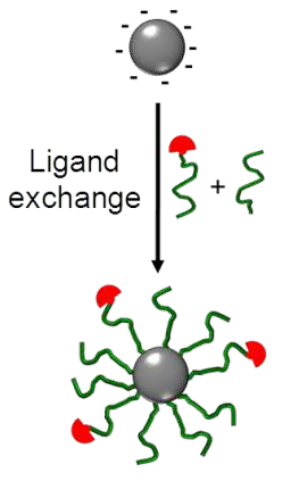

Biotin-PSPP-AgNP

PSPP

Biotin-PSPP

Fig. 1. Elaboration of the electrochemical label. (a) Synthesis of zwitterionic polymers, PSPP by RAFT polymerization and biotin-PSPP by

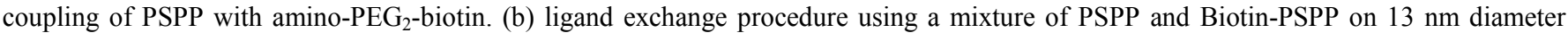
silver nanoparticles.

Zwitterionic polymers were synthesized by reversible addition fragmentation chain transfer (RAFT) polymerization of $N, N^{\prime}$ dimethyl(methacrylamido propyl)ammonium propanesulfonate (SPP) monomers using 4-cyanopentanoic acid dithiobenzoate (CTP) as RAFT agent. The RAFT agent used in this work is essential to allow synthesis of zwitterionic polymers (PSPP) with wellcontrolled average molar mass, dispersity and end-functionality. The as-synthesized PSPP were biofunctionalized with amino- $\mathrm{PEG}_{2}$ biotin (biotin-PSPP) via peptidic coupling (Fig. 1a). The characterization of the synthesized and modified polymers using size exclusion chromatography and NMR spectroscopy is shown in Fig. $\mathrm{S} 1$ and $\mathrm{S} 2$ and table $\mathrm{S} 1$ in ESI $\uparrow$. Then, the electrochemical label is obtained by ligand exchange procedure with a mixture of PSPP and biotin-PSPP on $13 \mathrm{~nm}$ diameter silver nanoparticles (Fig. 1b). The prepared biotin-PSPP-AgNP exhibit an excellent colloidal stability in high ionic strength solution as confirmed by the UV-vis spectra thanks to the properties of zwitterionic polymer chains (Fig. S4, $\mathrm{ESI} \dagger)^{10}$.

The electrochemical biosensor was elaborated step by step as follows (scheme 1): gold disk electrodes of $500 \mu \mathrm{m}$ diameter were biotinylated using sulfo-NHS-SS-biotin and then used to immobilize avidin protein, which was employed as a model target for biosensing tests. Finally, the electrochemical labels, biotin-PSPP-AgNP, were added by a second biorecognition between avidin and biotin. The electrode modification was followed step by step by cyclic voltammetry $(\mathrm{CV})$ and electrochemical impedance spectroscopy (EIS) measurements employing $\mathrm{Fe}(\mathrm{CN})_{6}{ }^{3-/ 4-}$ in $\mathrm{PBS}$ as redox probe, (Fig. 2). The successive modification steps of the electrode with biotin and avidin induce a decrease of the current and an increase of the potential difference between oxidation and reduction peaks, both indicating a slower electron transfer due to hindrance and characteristics of a modification of the electrode. The electrode modification was also validated by EIS measurements (Fig. 2b). Here, the small semicircle observed for bare gold electrode gradually increases after each modification indicating the progressively more difficult mass transfer of $\mathrm{Fe}(\mathrm{CN})_{6}{ }^{3-/ 4-}$ and consequently the effective biotinylation followed by avidin immobilization.
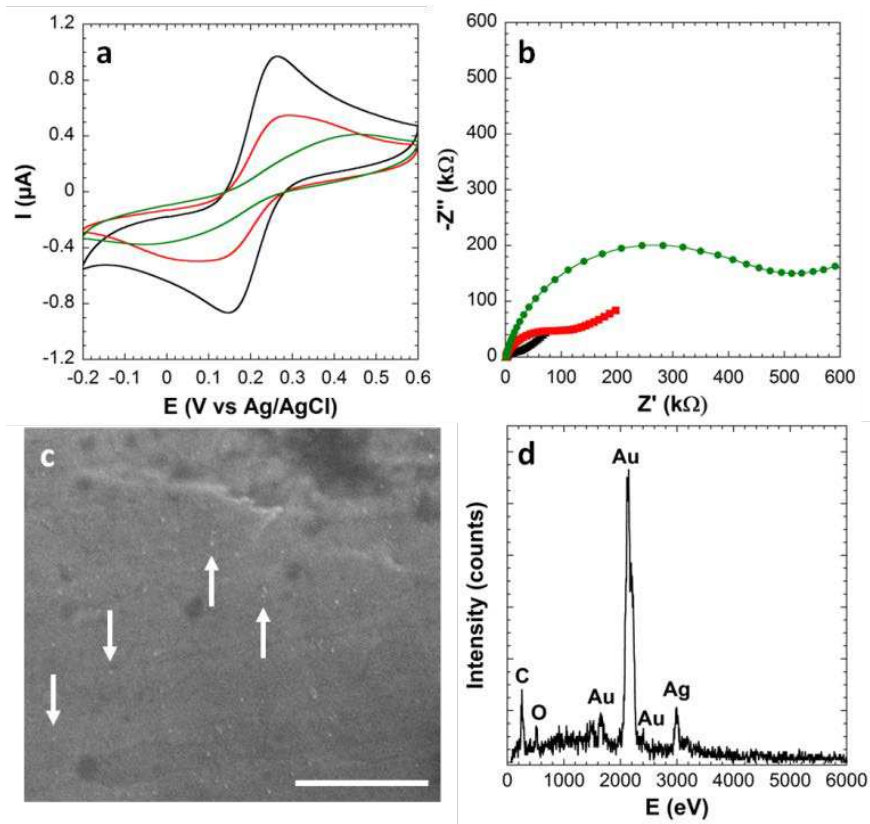

Fig. 2 (a) Cyclic voltammograms of various modified electrodes in $0.1 \mathrm{M}$ PBS pH 7.0 solution containing $1 \mathrm{mM} \mathrm{Fe}(\mathrm{CN})_{6}{ }^{3-/ 4-}$ at a scan rate of $50 \mathrm{mV} \mathrm{s}^{-1}$ : gold electrode (black), Au/Biotin (red), $\mathrm{Au} /$ Biotin/Avidin (green). (b) Nyquist plots corresponding to various modified electrodes in $0.1 \mathrm{M}$ PBS pH 7.0 solution containing $1 \mathrm{mM}$ $\mathrm{Fe}(\mathrm{CN})_{6}^{3-/ 4-}$ around $0.24 \mathrm{~V}$ : gold electrode (black), Au/Biotin (red), Au/Biotin/Avidin (green). (c) SEM images of biosensor's gold electrodes functionalized with biotin-PSPP-AgNP, [Avidin] $=15$ $\mathrm{nM}$. The arrows represent silver nanoparticles deposited on gold electrodes. The scale bar is $1 \mu \mathrm{m}$. (d) EDX spectrum of the biosensor's electrode.

The presence of biotin-PSPP-AgNP on gold electrodes after the last immobilization step was confirmed by SEM images (Fig. 2c). The 
EDX spectrum shows a peak related to silver at $2964 \mathrm{eV}$ which proves the presence of immobilized biotin-PSPP-AgNP on the modified electrode (Fig. 2d). The estimated density is 10 nanoparticles per $\mu \mathrm{m}^{2}$. This absence of a full monolayer of nanoparticles is coherent with previous results reporting that dipping an electrode modified with a self-assembled monolayer (SAM) made from NHS-SS-biotin in avidin low concentration solutions $(<10$ $\mathrm{nM}$ ) did not lead to a full avidin monolayer ${ }^{28}$. In addition, it is necessary to take into account a desorption of avidin when biotinylated nanoparticles are introduced due to a competitive binding of avidin between biotin immobilized on the electrode and biotin from labels. Such a phenomenon was also described and the authors reported that a $1 \mathrm{mM}$ biotin solution is able to remove almost a monolayer of avidin. ${ }^{29}$ In our study, the NP concentration is estimated to be at nanomolar level which explains we do not remove all the avidin. Sensing tests of the elaborated biosensor using biotinPSPP-AgNP as electrochemical labels were carried out by performing cyclic voltammetry in phosphate buffer solution (Fig. $3 a)$. The cyclic voltammogram presents an oxidation peak with a maximum at $210 \mathrm{mV}$ and a reduction peak at $-5 \mathrm{mV}$. These peaks are characteristics respectively of oxidation of silver coated with PSPP in PBS medium in a silver precipitate and of the reverse reaction. This result shows that silver from the hybrid label developed in this study can be electrochemically oxidized. This signal is only related to the specific adsorption of biotin-PSPP-AgNP via biotin-avidin complexation. Indeed, sensing tests carried out with $\mathrm{Au}$ and $\mathrm{Au}$ /Biotin electrodes after their dipping in a biotin-PSPPAgNP suspension do not induce any oxidation or reduction peak (Fig. S7 and S8, ESI $\dagger$ ).
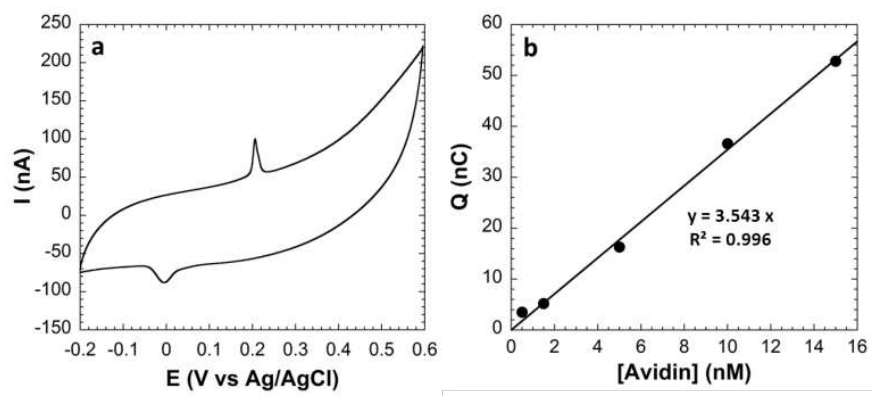

Fig. 3 (a) Cyclic voltammogram on Au/Biotin/Avidin/Biotin-PSSPAgNP in $0.1 \mathrm{M}$ PBS pH 7.0 solution at a scan rate of $50 \mathrm{mV} \mathrm{s}^{-1}$, [Avidin] $=5 \mathrm{nM}$. (b) Calibration curve of the relationship between oxidation charge of AgNP and avidin concentration used in sandwich elaboration.

In addition, the oxidation charge of assemblies realized with various amount of avidin was investigated. The charge variation with the avidin concentration is plotted in Fig. 3b. It is noteworthy a straightline is obtained and it constitutes a calibration curve for determination of avidin. It should be noticed that the calibration curve has not been extended to higher avidin concentrations to characterize the linear calibration range as we focused on the electrochemical oxidation of silver nanoparticles. The limit of quantification obtained here is $1.5 \mathrm{nM}$, corresponding to $90 \mathrm{ng} \mathrm{mL}^{-1}$ or $500 \mathrm{pM}$ were detected. Moreover, surface density of the immobilized nanoparticles was estimated to be 10 nanoparticles per $\mu \mathrm{m}^{2}$ and considering the electrode geometric area of $196300 \mu \mathrm{m}^{2}$ and an average of $100000 \mathrm{Ag}$ atoms per nanoparticle, the oxidation charged expected from this sensor is $32 \mathrm{nC}+/-5$. This value is slightly lower than the experimental value determined from cyclic voltammetry but gives confidence to the high rate of silver nanoparticles oxidation. This last conclusion confirms intense signal can be obtained using silver nanoparticles as expected.

In summary, we developed a new versatile label for electrochemical biosensors based on zwitterionic polymer-coated silver nanoparticles. The zwitterionic polymer of the coating, synthesized by RAFT polymerization, provides both, versatility as it can be easily biofunctionalized with various bioreceptors directed towards new target molecules, and high colloidal stability. On the other hand, the silver core contributes to signal enhancement and its electrochemical oxidation allows easy sensing processes. This presented work paves the way for the detection of biological marker traces like proteins directly in biological media.

This project was financially supported by Région Ile de France (C'nano IdF). SEM-FEG instrument was facilitated by the IMPC (Institut des Matériaux de Paris Centre FR2482) financially supported by the C'Nano projects of the Region Ile-de-France.

The authors thank $\mathrm{X}$. $\mathrm{Xu}$ and $\mathrm{D}$. Montero for technical assistance with electron microscopy and EDX analysis and M. Hanafi for SEC analysis.

\section{Notes and references}

${ }^{a}$ Laboratoire de Physicochimie des Polymères et Interfaces (EA2528), Institut des Matériaux, Université de Cergy-Pontoise, 5 mail Gay Lussac, 95031, Neuville-sur-Oise, France. E-mail : philippe.banet@u-cergy.fr

${ }^{b}$ ESPCI ParisTech, PSL Research University, Sciences et Ingénierie de la Matière Molle, CNRS UMR 7615, 10 rue Vauquelin, F-75231 Paris cedex 05, France. E-mail : nicolas.sanson@espci.fr

c Sorbonne-Universités, UPMC Univ Paris 06, SIMM, 10 rue Vauquelin, F-75231 Paris cedex 05, France.

$\dagger$ Electronic Supplementary Information (ESI) available: Experimental details for synthesis, biofunctionalization and characterization of zwitterionic polymers and hybrid nanoparticles. Biosensor elaboration and voltammograms. See DOI: 10.1039/c000000x/

1. A. P. F. Turner, Chemical Society Reviews, 2013, 42, 3184-3196.

2. B. V. Chikkaveeraiah, A. A. Bhirde, N. Y. Morgan, H. S. Eden and X. Chen, ACS Nano, 2012, 6, 6546-6561.

3. E. Katz and I. Willner, Angewandte Chemie International Edition, 2004, 43, 6042-6108.

4. Y. Li, H. Schluesener and S. Xu, Gold Bulletin, 2010, 43, 29-41.

5. A. N. Shipway, E. Katz and I. Willner, ChemPhysChem, 2000, 1, 1852.

6. M. Pumera, A. Ambrosi, A. Bonanni, E. L. K. Chng and H. L. Poh, Trends in Analytical Chemistry, 2010, 29, 954-965. 
7. G. Wang, Y. Wang, L. Chen and J. Choo, Biosensors and Bioelectronics, 2009, 25, 1859-1868.

8. X. Luo, A. Morrin, A. J. Killard and M. R. Smyth, Electroanalysis, 2006, 18, 319-326.

9. J. Wang, Analyst, 2005, 130, 421-426.

10. S. Alwarappan, A. Erdem, C. Liu and C. Z. Li, Journal of Physical Chemistry C, 2009, 113, 8853-8857.

11. M. Dequaire, C. Degrand and B. Limoges, Analytical Chemistry, 2000, 72, 5521-5528.

12. J. Wang, R. Polsky and D. Xu, Langmuir, 2001, 17, 5739-5741.

13. J. A. Hansen, J. Wang, A.-N. Kawde, Y. Xiang, K. V. Gothelf and G. Collins, Journal of the American Chemical Society, 2006, 128, 2228-2229.

14. J. Wang, G. Liu, M. R. Jan and Q. Zhu, Electrochemistry Communications, 2003, 5, 1000-1004.

15. M. Wang, C. Sun, L. Wang, X. Ji, Y. Bai, T. Li and J. Li, Journal of Pharmaceutical and Biomedical Analysis, 2003, 33, 11171125.

16. H. Karadeniz, A. Erdem, A. Caliskan, C. M. Pereira, E. M. Pereira and J. A. Ribeiro, Electrochemistry Communications, 2007, 9, 2167-2173.

17. L. Kashefi-Kheyrabadi and M. A. Mehrgardi, Biosensors and Bioelectronics, 2012, 37, 94-98.

18. B. P. Ting, J. Zhang, Z. Gao and J. Y. Ying, Biosensors and Bioelectronics, 2009, 25, 282-287.

19. J. Ghilane, F.-R. F. Fan, A. J. Bard and N. Dunwoody, Nano Letters, 2007, 7, 1406-1412.

20. T. H. Degefa, S. Hwang, D. Kwon, J. H. Park and J. Kwak, Electrochimica Acta, 2009, 54, 6788-6791.

21. F. Gao, Z. Zhu, J. Lei, Y. Geng and H. Ju, Biosensors and Bioelectronics, 2013, 39, 199-203.

22. M. Javanbakht, F. Divsar, A. Badiei, F. Fatollahi, Y. Khaniani, M. R. Ganjali, P. Norouzi, M. Chaloosi and G. M. Ziarani, Electrochimica Acta, 2009, 54, 5381-5386.

23. G. Lai, L. Wang, J. Wu, H. Ju and F. Yan, Analytica Chimica Acta, 2012, 721, 1-6.

24. E. Muro, T. Pons, N. Lequeux, A. Fragola, N. Sanson, Z. Lenkei and B. Dubertret, J. Am. Chem. Soc., 2010, 132, 4556-4557.

25. Z. G. Estephan, P. S. Schlenoff and J. B. Schlenoff, Langmuir, 2011, 27, 6794-6800.

26. L. Mi and S. Y. Jiang, Angew. Chem., Int. Ed., 2014, 53, 1746-1754.

27. K. P. Garcia, K. Zarschler, L. Barbaro, J. A. Barreto, W. O'Maley, L. Spiccia, H. Stephan and B. Graham, Small, 2014, 10, 25162529.

28. H. Kuramitz, K. Sugawara and S. Tanaka, Electroanalysis, 2000, 12, 1299-1303.

29. V. H. Perez-Luna, M. J. O'Brien, K. A. Opperman, P. D. Hampton, G. P. Lopez, L. A. Klumb and P. S. Stayton, Journal of the American Chemical Society, 1999, 121, 6469-6478. 